\title{
25 Research Soure \\ Functional analysis of miRNA-146b during myotube differentiation in chicken myoblasts
}

\section{Jeong Hyo Lee}

Seoul National University

\section{Seo Woo Kim}

Seoul National University

Ji Seon Han

Seoul National University

\section{Seung Pyo Shin}

Seoul National University

\section{Sang In Lee}

Kyungpook National University

Tae Sub Park ( $\square$ taesubpark@snu.ac.kr)

Seoul National University https://orcid.org/0000-0002-0372-5467

\section{Research article}

Keywords: miRNA-146b, overexpression, chicken myoblast cell, muscle differentiation

Posted Date: December 13th, 2019

DOl: https://doi.org/10.21203/rs.2.18746/v1

License: (c) (i) This work is licensed under a Creative Commons Attribution 4.0 International License. Read Full License

Version of Record: A version of this preprint was published at BMC Molecular and Cell Biology on May 29th, 2020. See the published version at https://doi.org/10.1186/s12860-020-00284-z. 


\section{Abstract}

In poultry industry as well as livestock, the precise genetic information is being required for improving the economic traits. Thus, functional genomic studies are widely conducted to build the genetic and genomic information for faster, healthier and more-efficient animal production. Especially, chicken myoblast cells which are required to muscle development and regeneration are important because chicken growth performance is closely related to muscle mass. In this study, we induced expression of microRNA-146b (miR-146b) mediated by piggyBac transposon system in chicken myoblast (pCM cells). Subsequently, we analyzed and compared the proliferation and differentiation capacity, and also examined the expression patterns of related genes between regular pCM (rpCM) cells and miR-146b overexpressing pCM (pCM$146 \mathrm{~b}$ OE) cells. The overexpression of miR-146b showed that the increased proliferation and up-regulated gene expression related to cell proliferation. In addition, the next generation sequencing (NGS) analysis were performed to compare the global gene expression patterns between rpCM cells and $\mathrm{pCM}-146 \mathrm{~b} \mathrm{OE}$ cells. We found that the higher proliferation rate of pCM-146b OE cells resulted from up-regulation of the cell cycle related gene sets. Moreover, miR-146b overexpression indicated that inhibitory effect of myotube differentiation in chicken myoblast cells. Collectively, these results demonstrated that miR-146b is closely related to proliferation and differentiation of chicken myogenic cells as a modulator of posttranscription.

\section{Introduction}

Since the whole-genome sequencing information of avian species were revealed, the numerous suggestions such as increasing muscle mass, enhancing muscle regeneration capability and reducing fatty acid accumulation have been proposed to improve growth performance. Especially, exploring the useful genes or genetic markers is important to understand the biological function(s) and regulatory pathway(s) to determine the economically important traits in poultry industry (International Chicken Genome Sequencing 2004; Claire D 'Andre et al. 2013; Rubin et al. 2010). Thus, the functional genomic study is one of the powerful and effective methods to investigate the modulatory mechanisms between cell proliferation and differentiation particularly in skeletal muscles (Kim et al. 2017; Kim et al.2017; Lee et al. 2017; Park et al.2018). Our study was conducted in chicken myoblasts which were derived from embryonic tissue. Myoblasts are derived from satellite cells which are known as a myogenic precursor (Zammit et al. 2006). In quiescent satellite cell stage, Pax7 which is a critical marker of undifferentiated myoblast is highly expressed. After activated, they start to proliferate with decreasing of Pax7 expression and increasing of MyoD expression which is one of the myogenic regulatory factors (MRFs). Then, they enter the stage of terminal differentiation. In this stage, the expression of MyoD is decreased and those of terminal differentiation makers such as Myogenin and Desmin are increased. Eventually, myoblast cells form new myotubes and subsequently, new myotubes form new myofiber. (Olguin and Pisconti 2012). Therefore, Myoblasts are regarded as intriguing cells because they are closely related with muscle growth that is one of the most economic values of domestic animal. 
The microRNAs (miRNAs) are a small non-coding RNA molecule that can regulate the targeted gene expression by the specific mRNA degradation and translational inhibition (Bartel 2009; Boldin and Baltiomre 2012; Izaurralde 2015). There were numerous reports on modulations of miRNAs for developmental and cellular processes such as cell proliferation, differentiation and tissue specification (Stefani and Slack 2008; Felekkis et al. 2010; Mineno et al. 2006). In addition, some miRNAs were reported to control myogenesis process in mammals (Kim et al. 2006, Chen et al. 2010). miRNA-146b (miR-146b) is well-conserved in most vertebrates and has many biological functions such as innate immunity, inflammation and cell senescence (Taganov et al. 2006; Bhaumik et al. 2009; Perry et al. 2009). Recently, miR-146b was known as a key regulator for muscle regeneration and myoblast differentiation in mouse (Khanna et al. 2014).

However, additional research is required because it is not clear how miR-146b affect myogenic differentiation and there are no reports about effect of miR-146 in chicken myogenesis. Thus, in this study, we designed and constructed the microRNA (miRNA) expression vector system to overexpress the miR-146b in chicken myoblast cells. For functional genomics study, the piggyBac transposon system which previous study demonstrated as an efficient transgene delivery system was used (Park et al. 2017; Park et al. 2019).

\section{Materials And Methods}

\section{Primary chicken myoblast ( $\mathrm{pCM}$ ) cell culture and induction of myotube differentiation}

Primary chicken myoblast ( $\mathrm{pCM}$ ) cells were isolated from pectoralis major of 10-day-old male chick embryos and maintained in Medium 199 (Invitrogen), supplemented with 10\% fetal bovine serum (FBS; HyClone), $2 \%$ chicken serum (Sigma-Aldrich) and $1 \times$ antibiotic-antimycotic (Invitrogen) (Lee et al. 2019). These cells were cultured in an incubator $37^{\circ} \mathrm{C}$ in an atmosphere of $5 \% \mathrm{CO}_{2}$ and $60-70 \%$ relative humidity. To induce myotube differentiation at $80 \%$ confluency of cells, after washed one time by using PBS, the differentiation medium containing $0.5 \%$ FBS and $1 \times$ antibiotic-antimycotic was changed. The differentiation medium was replaced with fresh differentiation medium daily.

\section{Construction of miR146b overexpression vector}

To overexpress chicken microRNA-146b (miR-146b), miR-146b were inserted into the piggyBac transposon transgene expression system vector (System Biosciences, Palo Alto, CA, USA) after Asc I digestion and ligation (piggyBac CMV-GFP-miRNA-146b). The cytomegalovirus (CMV) and elongation factor-1 (EF-1) promoter controlled the expression of GFP-miRNA-146b and puromycin resistance gene, respectively (Fig. 1A). The miRNA-146b were synthesized as $5^{\prime}$-gct ggt gac gtc ccc tat gga att gag ttc tcc gct gtg aca ctt caa act gag aac tga att cca tag gcg atg tgg tca gca - 3' (Bionics, Seoul, Korea). 


\section{Transfection and selection of miR-146b overexpression vector}

To establish miR-146b expressing myoblast cells, the transgene expression vector, piggyBac CMV-GFP (control) or piggyBac CMV-GFP-miRNA-146b, was co-transfected with piggyBac transposase using Lipofectamine 3000 (Invitrogen) according to the manufacturer's protocol. After pCM cells were washed with phosphate-buffered saline (PBS) and refreshed with $2 \mathrm{ml}$ of the culture media without antibioticantimycotic, the plasmid DNA-lipid complex consisting of $7.5 \mu \mathrm{l}$ Lipofectamine 3000 reagent in $250 \mu \mathrm{l}$ Opti-MEM (Invitrogen) and 10 ul P3000 reagent with 2.5ug piggyBac transgene vector and piggyBac transposase plasmid in $250 \mathrm{ul}$ Opti-MEM was added to each well. One day after lipofection, $10 \mathrm{ug} / \mathrm{ml}$ puromycin was added to select the cells stably transfected with the transgene.

\section{Quantitative RT-PCR analysis}

Total RNA was extracted using Trizol reagent (Invitrogen) according to the manufacturer's instructions. Total RNA was quantified using a NanoDrop 2000 (Thermo Scientific), and 2ug RNA were used for cDNA synthesis using random primers (Invitrogen) under standard conditions. Quantitative RT-PCR for miRNA was conducted by using High-specificity miRNA QPCR Core Reagent Kit (Agilent Technology, Santa Clara, CA, USA). Each 20 ul RT-PCR reaction mix contained 2 ul cDNA, 2.5 ul PCR buffer, 1 ul dNTP mixture (2.5 mM), 1unit Taq DNA polymerase, and 10 pmol forward and reverse primer (Table 1). Quantitative RTPCR analysis was performed using the iCycler iQ Real-time PCR detection system (Bio-Rad) and EvaGreen (Biotium, Fremont, CA, USA). The PCR parameters were as follows: an initial incubation at $94^{\circ} \mathrm{C}$ for 5 min, followed by 40 cycles at each condition (Table 1 ). The reaction was terminated by a final incubation at $72^{\circ} \mathrm{C}$ for $10 \mathrm{~min}$, and melting curve profiles were analyzed for the amplicons. 
Table 1

List of primer sets for PCR analysis.

\begin{tabular}{|c|c|c|c|c|}
\hline Gene & Forward & Reverse & $\begin{array}{l}\text { Annealing } \\
\text { Temp. }\left({ }^{\circ} \mathrm{C}\right)\end{array}$ & $\begin{array}{l}\text { PCR } \\
\text { size(bp) }\end{array}$ \\
\hline Actin & GATGATATTGCTGCGCTCGT & GTGCTCCTCAGGGGCTACTC & $60^{\circ} \mathrm{C}$ & 618 \\
\hline Pax7 & AGGTACCAAGAGACGGGCTC & CTCGGCAGTGAAAGTGGTCC & $60^{\circ} \mathrm{C}$ & 411 \\
\hline MyoD & ACACGTCGGACATGCACTTC & TCTGACTCCCCGCTGTAGTG & $55^{\circ} \mathrm{C}$ & 433 \\
\hline SMAD4 & GCCCACCACAACATACTCCT & GCACTTGAGATCGAAGGCGT & $60^{\circ} \mathrm{C}$ & 315 \\
\hline NUMB & GCTGCCCCAACTACTACTGC & ACAGGGCACTAATGCTGTCC & $55^{\circ} \mathrm{C}$ & 310 \\
\hline ADCK3 & CTGTGCAGCAAACATGTCCT & GGCATCTTCCATTTCCTTGA & $60^{\circ} \mathrm{C}$ & 366 \\
\hline RRM2B & GGACCTTCCTCACTGGAACA & TCCACTTCAGAGCCCAGTCT & $55^{\circ} \mathrm{C}$ & 308 \\
\hline SGCB & CACGAGTTTCATCTGCCAAA & TCACTTGCACCTTGAACAGC & $55^{\circ} \mathrm{C}$ & 343 \\
\hline CCND3 & TTTCTGGATGCTGGAGGTGT & ATGCAGAGCTTCTCCACAGT & $60^{\circ} \mathrm{C}$ & 195 \\
\hline IRF2 & AATGCAGAGGGACGACTTCA & ACTGGGTGATGTCTGACGTT & $60^{\circ} \mathrm{C}$ & 301 \\
\hline WNT5A & GATACCGCTTTGCCAAGGAG & GCCTACCTTGCGGAAATCAG & $60^{\circ} \mathrm{C}$ & 224 \\
\hline PDGFRB & AGAGCTAGAGGACAGTGGGA & CATTGGAAGCTCGGATGGTG & $60^{\circ} \mathrm{C}$ & 359 \\
\hline CCNB2 & TGAAATGTTGGTGGTAGGGC & GGAACAAGTATGCAAGTAGC & $60^{\circ} \mathrm{C}$ & 209 \\
\hline CDC20 & GAGTCCTGAACCTGACCATG & CTGTACAGTGTGTAAGCCCA & $60^{\circ} \mathrm{C}$ & 221 \\
\hline KIF23 & ССTTTCTTGTCAGGCCCTCT & TCTGTGAGCACGTTACCCTT & $60^{\circ} \mathrm{C}$ & 348 \\
\hline KPNA2 & ACACAGAGCAAGGGGTTACA & TCCAAATTCAGGGCAATGCT & $60^{\circ} \mathrm{C}$ & 332 \\
\hline PLK1 & CTGATGCTGTGGTGATGGTG & TCTCAACCTGGGCACGTTAA & $60^{\circ} \mathrm{C}$ & 316 \\
\hline TOP2A & TCAACAAAGGCAGCAAGGTC & GGCTCGATTCATCCTGGAGA & $60^{\circ} \mathrm{C}$ & 348 \\
\hline ID1 & TGATCGACTACATCTGGGACC & TCTGAGAAGGTTACGAGCCG & $60^{\circ} \mathrm{C}$ & 251 \\
\hline \multicolumn{3}{|c|}{$\begin{array}{l}\text { sno RNA : GGGATGTAAAAAAATACTTGCTATC } \\
\text { miR-146b : UGAGAACUGAAUUCCAUAGGCG }\end{array}$} & $60^{\circ} \mathrm{C}$ & \\
\hline
\end{tabular}

\section{Western blotting}

Total protein was extracted with $1 \times$ radioimmunoprecipitation (RIPA) lysis buffer and separated on a $10 \%$ polyacrylamide gel followed by transfer to a nitrocellulose membrane (Bio-Rad, Hercules, CA, USA). The primary antibodies used were mouse anti- $\beta$-actin (Santa Cruz Biotechnology, Dallas, TX, USA), anti-Pax7 (R\&D Systems, Minneapoils, MN, USA), anti-MyoD (Santa Cruz Biotechnology), anti-Desmin (Novus Biologicals, Littleton, CO). HRP-conjugated anti-mouse IgG or anti-rabbit IgG (Bio-Rad) were used as 
secondary antibodies. The blots were treated with ECL substrate solutions and exposed in a ChemiDoc XRS System (Bio-Rad) to detect chemiluminescence.

\section{Cell growth curve and statistical analysis}

To calculate cell growth curve, pCM-GFP or pCM-146b OE cells were subcultured in 24-well culture plates $\left(2 \times 10^{4}\right.$ cells/well). Total cell number of each well was counted during in vitro culture of 5 days.

\section{Library preparation and sequencing}

For total mRNAs from regular pCM cells or pCM-146b OE cells, the construction of library was performed using QuantSeq 3' mRNA-Seq Library Prep Kit (Lexogen, Inc., Austria) according to the manufacturer's instructions. In brief, each $500 \mathrm{ng}$ total RNA were prepared and an oligo-dT primer containing an Illuminacompatible sequence at its $5^{\prime}$ end was hybridized to the RNA and reverse transcription was performed. After degradation of the RNA template, second strand synthesis was initiated by a random primer containing an Illumina-compatible linker sequence at its $5^{\prime}$ end. The double-stranded library was purified by using magnetic beads to remove all reaction components. The library was amplified to add the complete adapter sequences required for cluster generation. The finished library is purified from PCR components. High-throughput sequencing was performed as single-end 75 sequencing using NextSeq 500 (Illumina, Inc., USA).

\section{Data analysis}

QuantSeq 3' mRNA-Seq reads were aligned using Bowtie2 (Langmead and Salzberg 2012). Bowtie2 indices were either generated from genome assembly sequence or the representative transcript sequences for aligning to the genome and transcriptome. The alignment file was used for assembling transcripts, estimating their abundances and detecting differential expression of genes. Differentially expressed gene was determined based on counts from unique and multiple alignments using coverage in Bedtools (Gentleman et al. 2004). The RC (Read Count) data were processed based on quantile normalization method using EdgeR within R using Bioconductor (Quinlan et al. 2010). Gene classification was based on searches done by DAVID (http://david.abcc.ncifcrf.gov/) and Medline databases (http://www.ncbi.nlm.nih.gov). Using mRNA next-generation-sequencing (NGS) data, differentially expressed genes (DEGs) from regular pCM cells and pCM-146b OE cells were identified with a p-value cutoff at 0.001 and a fold change cutoff at 1.5. Protein-protein association was analyzed using STRING analysis to identify all functional interactions of DEGs (https://string-db.org).

\section{Statistical analysis}

Statistical analysis was conducted using the SAS version 9.4 software (SAS Institute, Cary, USA). The significance of differences was analyzed using a general linear model procedure and the differences among groups were deemed to be significant when $p<0.05$.

\section{Results}




\section{miR-146b overexpression in chicken myoblast cells}

Based on our previous report of miRNA expression system (Lee et al. 2019), we designed and constructed piggyBac transposon-mediated miR-146b overexpression vector (piggyBac CMV-GFP-miRNA-146b, Fig. 1A). Two copies of miR-146b were simultaneously transcribed with GFP transgene under CMV promoter (Fig. 1A). Thus, this miRNA expression cassette system could be efficiently utilized not only for overexpression of the targeted miRNA but also for GFP visualization in the transfected cells. Both of the stable transgene-expressing cells, regular pCM ( $r p C M)$ and miR-146b overexpression cells ( $\mathrm{pCM}-146 \mathrm{~b}$ OE cells) showed no difference of morphological features (Fig. 1B). Quantitative RT-PCR (qRT-PCR) was conducted to determine the overexpression of miR-146b in pCM-146b OE cells. The expression level of miR-146b was significantly up-regulated in pCM-146b OE cells compared to that of regular pCM (Fig. 1C).

\section{Characterization of pCM-146b OE cells in undifferentiated state}

To examine gene expression patterns of the myogenic markers and targets of miR-146b in the undifferentiated state, qRT-PCRs and Western blotting were performed and compared between regular pCM and pCM-146b OE cells. Based on miRBase (http://www.mirbase.org), we selected the predicted targets of miR-146b and analyzed the expression patterns in pCM-146b OE cells. All of the predicted target transcripts (SMAD4, NUMB, ADCK3, RRM2B and SGCB) were significantly down-regulated in pCM$146 \mathrm{~b}$ OE cells compared to those in regular pCM cells (Fig. 2A). The expression of Pax7 which is a critical marker of undifferentiated myoblast was down-regulated while expression level of MyoD which is one of the myogenic regulatory factors (MRFs) was up-regulated (Fig. 2B). Similar to qRT-PCR results, Western blotting showed the down-regulated and up-regulated expression pattern in Pax7 and MyoD, respectively (Fig. 2C). These results indicated that miR-146b could globally be involved in transcriptional regulation of myogenic genes in chicken myoblast cells.

\section{Overexpression of miR-146b improved the proliferation of chicken myoblast cells}

Intriguingly, pCM-146b OE cells showed the higher proliferative growth rate. To exclude influence of GFP which was inserted in miR-146b overexpression vectors, the proliferative analysis was compared between pCM-GFP cells and pCM-146b OE cells. The result showed that pCM-146b OE cells also have higher growth rate than that of pCM-GFP cells 3 days after in vitro culture (Fig. 3A). Furthermore, we analysis cell proliferation-related genes (CCND3, IRF2, WNT5A and PDGFRB) by qRT-PCR. All of transcripts which were reported as positive regular of proliferation were up-regulated in PCM-146b OE cells (Fig. 3B). These results suggested that miR-146b has an effect on the skeletal muscle proliferation in chicken myoblast cells.

\section{Global gene expression analysis by RNA sequencing in pCM-146b OE cells}


In next experiment, we conducted mRNA sequencing analysis to compare the global gene expression patterns between regular pCM and pCM-146b OE cells. From mRNA sequencing data, we sorted out a total 647 differentially expressed genes (DEGs) in which 291 and 356 DEGs were down-regulated and upregulated, respectively 356 (Fig. 4A). Figure 4B showed the scatter plot analysis for DEGs between regular pCM and $\mathrm{pCM}-146 \mathrm{~b}$ OE cells. Under the conditions with the up-regulated gene sets cut-off of fold change $\geq 1.5$ ( $p$ value $<0.001$ ) and the down-regulated gene sets cut-off of fold change $\leq 0.6$ ( $p$ value $<0.001)$, we identified 4 up-regulated and 2 down regulated gene sets based on the gene set enrichment analysis (GSEA, http://software.broadinstitute.org/gsea/index.jsp) (Table 2). Subsequently, these gene sets were compared by Heatmap visualization to examine the different expression patterns of gene sets between in between regular pCM and pCM-146b OE cells (Fig. 4C). To validate the DEGs from mRNA sequencing analysis, we selected and analyzed the gene expression patterns of six up-regulated genes (CCNB2, CDC20, KIF23, KPNA2, PLK1 and TOP2A) particularly related to cell cycle regulation. All of six cell cycle regulation related transcripts were highly up-regulated in $\mathrm{PCM}-146 \mathrm{~b}$ OE cells (Fig. 5A). To understand the functional interactions of the up-regulated genes and their neighbor genes, we applied STRING analysis to the interactions between these genes (Fig. 5B). These results supported that the effect of miR-146b on the skeletal muscle proliferation and also it influenced the regulatory pathways of cell cycling in chicken myoblast cells.

Table 2

List of up- and down-regulated gene sets.

\begin{tabular}{|llcl|}
\hline $\begin{array}{l}\text { Up-regulated Gene } \\
\text { Sets Name }\end{array}$ & Description & Count. & $\begin{array}{l}\text { p- } \\
\text { value }\end{array}$ \\
\hline E2F targets & $\begin{array}{l}\text { Genes encoding cell cycle related targets of E2F } \\
\text { transcription factors. }\end{array}$ & 24 & $\begin{array}{l}6.09 \mathrm{E}- \\
23\end{array}$ \\
\hline G2/M checkpoint & $\begin{array}{l}\text { Genes involved in the G2/M checkpoint, as in progression } \\
\text { through the cell division cycle. }\end{array}$ & 24 & $\begin{array}{l}6.09 \mathrm{E}- \\
23\end{array}$ \\
\hline Mitotic spindle & Genes important for mitotic spindle assembly. & 13 & $1.23 \mathrm{E}-$ \\
\hline MYC targets V1 & A subgroup of genes regulated by MYC - version1 (V1). & 13 & 09 \\
\hline $\begin{array}{l}\text { Down-regulated } \\
\text { Gene Sets Name }\end{array}$ & Description & Count. & $\begin{array}{l}\text { p- } \\
\text { value }\end{array}$ \\
\hline $\begin{array}{l}\text { Xenobiotic } \\
\text { metabolism }\end{array}$ & Genes encoding proteins involved in processing of drugs \\
\hline $\begin{array}{l}\text { Fatty acid } \\
\text { metabolism }\end{array}$ & and other xenobiotics. & 5 & $\begin{array}{l}8.56 \mathrm{E}- \\
04\end{array}$ \\
\hline
\end{tabular}

\section{Overexpression of miR-146b influences myotube differentiation in chicken myoblast cells}


Subsequently, we compared and analyzed the myotube differentiation capacity between regular pCM and pCM-146b OE cells. Overexpression of miR-146b dramatically reduced the myotube differentiation and formation during myogenic process in pCM-146b OE cells (Fig. 6). pCM-146b OE cells showed lower number of the differentiated myotubes and less myotube differentiation formation compared to regular pCM cells (Fig. 6A). The area of differentiated myotubes was significantly decreased in pCM-146b OE cells after 4 days of myogenic induction (Fig. 6B). Western blotting results after the myogenic differentiation similarly showed the expression patterns in the undifferentiated stage (Fig. 7A). The expression of Pax7 was still down-regulated while the expression of MyoD was up-regulated in PCM-146b OE cells. Furthermore, Desmin, a myogenic differentiation terminal marker, was also down-regulated in pCM-146b OE cells. Additionally, we investigated expression of ID1 which is closely associated with muscle differentiation by binding E proteins (Fig. 7B). The expression of ID1 was significantly upregulated in $\mathrm{pCM}-146 \mathrm{~b}$ OE cells. These results demonstrated that overexpressed miR-146b affect the expression of genes that associated with myogenic differentiation and it agreed with the phenotypic difference between regular $\mathrm{PCM}$ and $\mathrm{pCM}-146 \mathrm{~b}$ OE cells after myogenic differentiation.

\section{Discussion}

Previous report suggested that mouse miR-146b promoted myogenic differentiation in muscle cells by regulating target genes that computationally predicted (Khanna et al. 2014). However, there was no data about the influences of chicken miR-146b in growth and differentiation of myoblast cells. Therefore, we investigated the effect of miR-146b by using overexpression method during myogenic differentiation in chicken myoblast cells. In previous study, the piggyBac transposon was demonstrate as stable system that integrate the miRNA expression transgene into the chicken genome (Park et al. 2017; Park et al. 2019; Lee et al. 2019). Thus, we used piggyBac transposon vector to overexpress the miR-146b and to deliver gene into the cells. The miR-146 OE pCM cells had similar morphological features to regular pCM cells. However, the overexpression of miR-146b showed different faster growth rate than regular one.

In the present study, $\mathrm{pCM}-146 \mathrm{~b}$ OE cells showed the higher expression of cell proliferation related genes (CCND3, IRF2, WNT5A, PDGFRB). In mouse vascular smooth muscle cells, PDGF-BB and PDGFRB regulated by miR-146b increased cell proliferation suggesting that miR-146b was required for PDGFinduced myogenic proliferation (Wang et al. 2015). Moreover, the PDGF-induced effects were also detected in skeletal muscle and stimulated skeletal muscle proliferation while inhibited myogenic differentiation (Yablonka-Reuveni et al. 1990). Thus, pCM-146b OE cells showed that the higher expression of PDGFRB mediated by miR-146b may enhance the cell proliferation and inhibit myogenic differentiation. To additional analysis, we conducted to RNA sequencing in regular and $\mathrm{pCM}-146 \mathrm{~b} \mathrm{OE}$ cells. Based on RNA sequencing data, we identified up-regulated gene sets which are closely related to cell cycle (Table 2). The transcriptional levels of cell cycle-related gene sets were up-regulated in $\mathrm{pCM}$ $146 \mathrm{~b} O E$ cells demonstrated that they were reciprocally associated with each other. Conclusively, miR146b appears to activate and stimulate the regulatory circuits of myogenic cell cycle and proliferation in chicken myoblast cells. 
In contrast, the myogenic differentiation could be suppressed because the myotube formation could be induced generally when the cell cycle is arrested (Andres and Walsh 1996). To analyze the biofunctionality of miR-146b during the myogenic differentiation process, we examined the myotube formation pattern and the related-gene expression after 4 days of differentiation. Although the expression level of MyoD which is one of myogenic regulatory factors (MRFs) for the determination of myogenic differentiation was up-regulated in the differentiated stage as well as in undifferentiated stage, $\mathrm{pCM}-146 \mathrm{~b}$ OE cells showed lower differentiation capacity compared to regular pCM cells 4 days of differentiation (Fig. 6). Similarly, the expression of desmin which is a myotube terminal differentiation marker was down-regulated in PCM-146b OE cells. Moreover, the expression of ID1 protein which is an inhibitor of myogenic differentiation in muscle was up-regulated in pCM-146b OE cells (Fig. 7). ID1 protein competitively suppresses $\mathrm{E}$ protein/MyoD complex because it has more high affinity for the E-protein than that of MyoD and so, it inhibits the myogenic differentiation (Benezra et al. 1990; Jen et al. 1992). mRNA and protein levels of MyoD expression was considerably up-regulated but the myotube differentiation was significantly decreased in pCM-146b OE cells (Figs. 6 and 7). This result could be possible that the up-regulation of ID1 protein controlled by miR-146b blocked the E protein/MyoD complex for myotube differentiating process. Furthermore, according to the bioinformatics-based analysis (http://www.mirbase.org), SIRT1 which is one of the target of miR-146b helps FOXO transcription factors to bind their target by deacetylation (Daitoku et al. 2011). FOXO3 binds promoter of ID1 directly to be transcriptionally repressed (Birkenkamp et al. 2007). This suggests that miR-146b could be indirectly control the expression of ID1 protein by inhibiting SIRT1/FOXO3 and the regulatory pathway of myogenic differentiation by regulating the expression of ID1 protein.

\section{Conclusion}

In this study, we produced the miR-146b overexpression chick myoblast cells and conducted a functional assay during myogenic proliferation and differentiation. Comparing with the regular pCM cells, pCM-146b OE cells show that higher proliferation rates and lower differentiation rates. pCM-146b OE cells have higher expression of cell proliferation related genes and cell cycle related genes. Especially, increasing of myogenic proliferation suggested that miR-146b could enhance the cell proliferation and inhibit myogenic differentiation by regulating the expression of PDGFRB. Furthermore, pCM-146b OE cells demonstrated higher expression of the ID1, it assumed that miR-146b could be indirectly control the myogenic differentiation by regulating the expression of ID1. These results suggest that miR-146b acts as key regulator of myogenic proliferation and differentiation in chicken.

\section{Declarations}

\section{Acknowledgements}

This work was carried out with the support of "Cooperative Research Program for Agriculture Science \& Technology Development (Project No. PJ01334801)" Rural Development Administration, Republic of Korea. 


\section{Author's contributions}

TSP participated in study design and coordination. JHL participated in the design of the study, carried out the experiments and wrote the first draft of the manuscript. SWK, JSH and SPS carried out and analyzed the experiments. TSP and SIL participated in writing the final version of the manuscript. All authors have read and approved the final manuscript.

\section{Conflict of interest}

The authors declare that they have no conflict of interest.

\section{Ethics approval}

This article does not contain any studies with human participants or animals performed by any of the authors.

\section{References}

1. Andres V, Walsh K (1996) Myogenin expression, cell cycle withdrawal, and phenotypic differentiation are temporally separable event that precede cell fusion upon myogenesis. J Cell Biol 132:657-666

2. Bartel DP (2009) MicroRNAs: target recognition and regulatory functions. Cell 136:215-233

3. Benezra R, Davis RL, Lockshon D, Turner DL, Weintraub H (1990) The protein Id: a negative regulator of helix-loop-helix DNA binding protein. Cell 61:49-59

4. Bhaumik D, Scott GK, Schokrpur S, Patil CK, Orjalo AV, Rodier F, Lithgow GJ, Campisi J (2009) MicroRNAs miR-146a/b negatively modulate the senescence-associated inflammatory mediators IL6 and IL-8. Aging (Albany NY) 1:402-411

5. Birkenkamp KU, Essafi A, van der Vos KE, da Costa M, Hui RC, Holstege F, Koenderman L, Lam EW, Coffer PJ (2007) FOXO3a induces differentiation of Bcr-Abl-transformed cells through transcriptional down-regulation of Id1. J Biol Chem 282:2211-2220

6. Boldin MP, Baltimore D (2012) MicroRNAs, new effectors and regulators of NF-kappaB. Immunol Rev 246:205-220

7. Chen JF, Tao Y, Li J, Deng Z, Yan Z, Xiao X, Wang DZ (2010) microRNA-1 and microRNA-206 regulate skeletal muscle satellite cell proliferation and differentiation by repressing Pax7. J Cell Biol 190:867879

8. Claire D'Andre H, Paul W, Shen X, Jia X, Zhang R, Sun L, Zhang X (2013) Identification and characterization of genes that control fat deposition in chickens. J Anim Sci Biotechnol 4:43

9. Daitoku H, Sakamaki J, Fukamizu A (2011) Regulation of FoxO transcription factors by acetylation and protein-protein interactions. Biochim Biophys Acta 1813:1954-1960

10. Felekkis K, Touvana E, Stefanou C, Deltas C (2010) microRNAs: a newly described class of encoded molecules that play a role in health and disease. Hippokratia 14:236-240 
11. Gentleman RC, Carey VJ, Bates DM, Bolstad B, Dettling M, Dudoit S, Ellis B, Gautier L, Ge Y, Gentry J, Hornik K, Hothorn T, Huber W, lacus S, Irizarry R, Leisch F, Li C, Maechler M, Rossini AJ, Sawitzki G, Smith C, Smyth G, Tierney L, Yang JY, Zhang J (2004) Bioconductor: open software development for computational biology and bioinformatics. Genome Biol 5:R80

12. International Chicken Genome Sequencing Consortium (2004) Sequence and comparative analysis of the chicken genome provide unique perspectives on vertebrate evolution. Nature 432:695-716

13. Izaurralde E (2015) GENE REGULATION. Breakers and blockers-miRNAs at work. Science 349:380382

14. Jen $Y$, Weintraub H, Benezra R (1992) Overexpression of Id protein inhibits the muscle differentiation program: in vivo association of Id with E2A protein. Genes Dev 6:1466-1479

15. Khanna N, Ge Y, Chen J. MicroRNA-146b promotes myogenic differentiation and modulates multiple gene targets in muscle cells. PloS one 9:e100657

16. Kim HK, Lee YS, Sivaprasad U, Malhotra A, Dutta A (2006) Muscle-specific microRNA miR-206 promotes muscle differentiation. J Cell Biol 174:677-687

17. Kim SW, Lee JH, Park BC, Park TS (2017) Myotube differentiation in clustered regularly interspaced short palindromic repeat/Cas9-mediate MyoD knockout quail myoblast cells. Asian-Australas J Anim Sci 30:1029-1036

18. Kim SW, Lee JH, Park TS (2017) Functional analysis of SH3 domain containing ring finger 2 during the myogenic differentiation of quail myoblast cells. Asian-Australas J Anim Sci 30:1183-1189

19. Langmead B, Salzberg SL (2012) Fast grpped-read alignment with Bowtie 2. Nat Methods 9:357-359

20. Lee JH, Kim SW, Park TS (2017) Myostatin gene knockout mediated by Cas9-D10A nickase in chicken DF1 cells without off-target effect. Asian-Australas J Anim Sci 30:743-748

21. Lee JH, Park JW, Kang KS, Park TS (2019) Forkhead box 03 promotes cell proliferation and inhibits myotube differentiation in chicken myoblast cells. Br Poult Sci 60:23-30.

22. Lee JH, Park JW, Seo ES, Kim HU, Han JS, Kim SJ Park TS, Park BC (2019) Functional efficacy analysis of Angelica gigas Nakai on chicken myoblast cells through cell-based in vitro assay. Anim Sci 90:903-912

23. Mineno J, Okamoto S, Ando T, Sato M, Chono H, Izu H, Takayama M, Asada K, Mirochnitchenko O, Inouye M, Kato I (2006) The expression profile of microRNAs in mouse embryos. Nucleic acids Res 34:1765-1771

24. Olguin HC, Pisconti A (2012) Marking the tempo for myogenesis: Pax7 and the regulation of muscle stem cell fate decisions. J Cell Mol Med 16:1013-1025

25. Park JW, Lee JH, Kim SW, Han JS, Kang KS, Kim SJ Park TS (2018) Muscle differentiation induced up-regulation of calcium-related gene expression in quail myoblasts. Asian-Australas J Anim Sci 31:1507-1515.

26. Park TS, Kim SW, Lee JH (2017) Efficient transgene expression system using a cumate-inducible promoter and Cre-loxP recombination in avian cells. Asian-Australas J Anim Sci 30:886-892. 
27. Park TS, Park J, Lee JH, Park JW, Park BC (2019) Disruption of G0/G1 switch gene 2 (G0S2) reduced abdominal fat deposition and altered fatty acid composition in chicken. FASEB J 33:1188-1198.

28. Perry MM, Williams AE, Tsitsiou E, Larner-Svensson HM, Lindsay MA (2009) Divergent intracellular pathways regulate interleukin-1 beta-induced miR-146a and miR-146b expression and chemokine release in human alveolar epithelial cells. FEBS Lett 583:3349-3355.

29. Quinlan AR, Clark RA, Sokolova S, Leibowitz ML, Zhang Y, Hurles ME, Mell JC, Hall IM (2010) Genome-wide mapping and assembly of structural variant breakpoints in the mouse genome. Genome Res 20:623-635.

30. Rubin CJ, Zody MC, Eriksson J, Meadows JR, Sherwood E, Webster MT, Jiang L, Ingman M, Sharpe T, Ka S, Hallbook F, Besnier F, Carlborg O, Bed'hom B, Tixier-Boichard M, Jensen P, Siegel P, LindbladToh K, Andersson L (2010) Whole-genome resequencing reveals loci under selection during chicken domestication. Nature 464:587-591.

31. Stefani G, Slack FJ (2008) Small non-coding RNAs in animal development. Nat Rev Mol Cell Biol 9:219-230.

32. Taganov KD, Boldin MP, Chang KJ, Baltimore D (2006) NF-kappaB-dependent induction of microRNA miR-146, an inhibitor targeted to signaling proteins of innate immune responses. Proc Natl Acad Sci U S A 103:12481-12486.

33. Wang $H$, Jiang $M$, Xu Z, Huang H, Gong P, Zhu H, Ruan C (2015) miR-146b-5p promotes VSMC proliferation and migration. Int J Clin Exp Pathol 8:12901-12907.

34. Yablonka-Reuveni Z, Balestreri TM, Bowen-Pope DF (1990) Regulation of proliferation and differentiation of myoblasts derived from adult mouse skeletal muscle by specific isoforms of PDGF. J Cell Biol 111:1623-1629.

35. Zammit PS, Partridge TA, Yablonka-Reuveni Z (2006) The Skeletal muscle satellite cell: the stem cell that came in from the cold. J Histchem Cytochem 54:1177-1191.

\section{Figures}


(A)

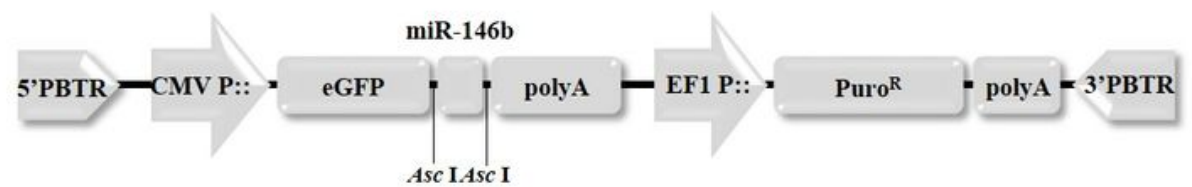

getggtgacg tec cetatggaattgagttctec getgtgacacttcaaac tgagaactgaattccatagg ega tgtggtcagca

Chicken miR-146b mature form : TGAGAACTGAATTCCATAGGCG

(B)

rpCM cells

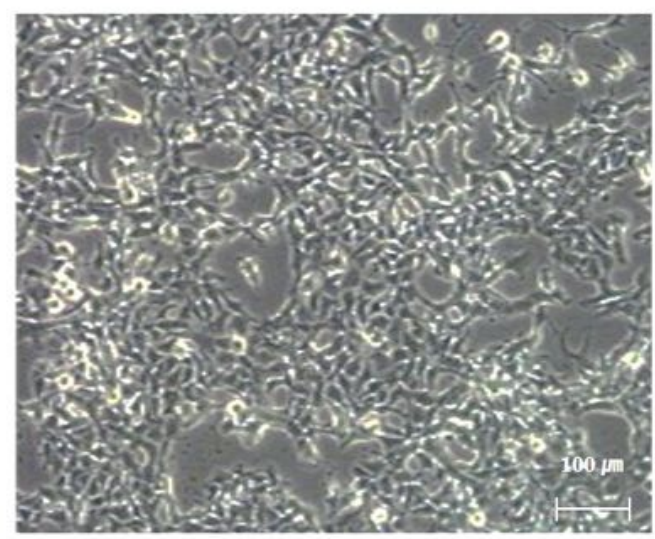

pCM-146b OE cells

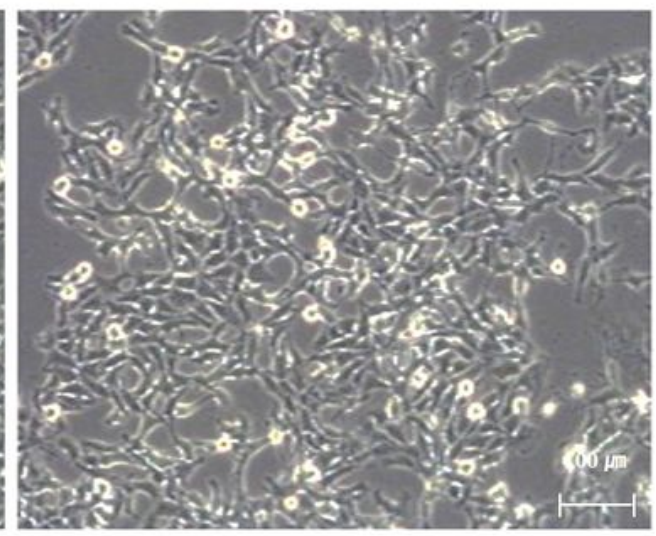

(C)

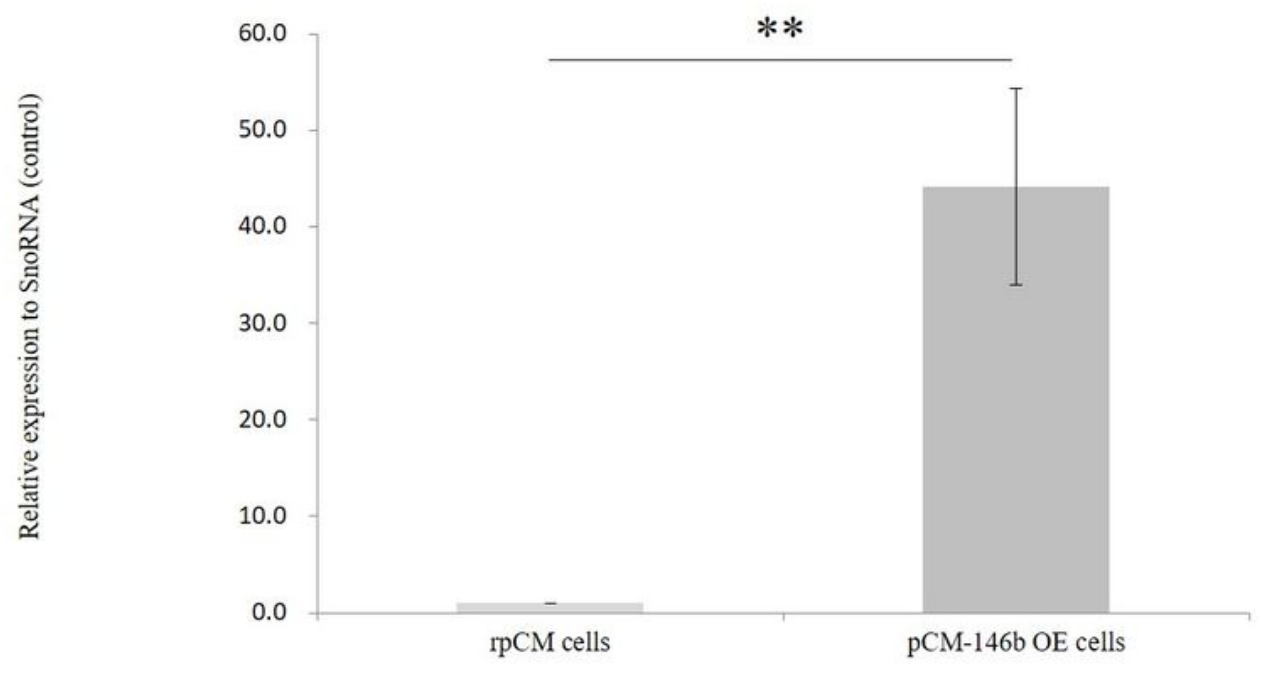

\section{Figure 1}

Design of chicken miRNA 146b expression vector and characterization of miR-146b overexpression primary chicken myoblast cells (A) The expression vector of piggyBac CMV-GFP-mir146b. The CMV and EF1 promoter controlled the expression of GFP-mir146b and puromycin resistance gene, respectively. (B) Morphology of the regular pCM (rpCM) and miR-146b OE pCM (pCM-146b OE) cells (scale bar = 100囚). 
(C) mRNA expression profile of miR-146b were compared between regular pCM and pCM-146b OE cells by qRT-PCR $(* * p<0.01)$.

(A)

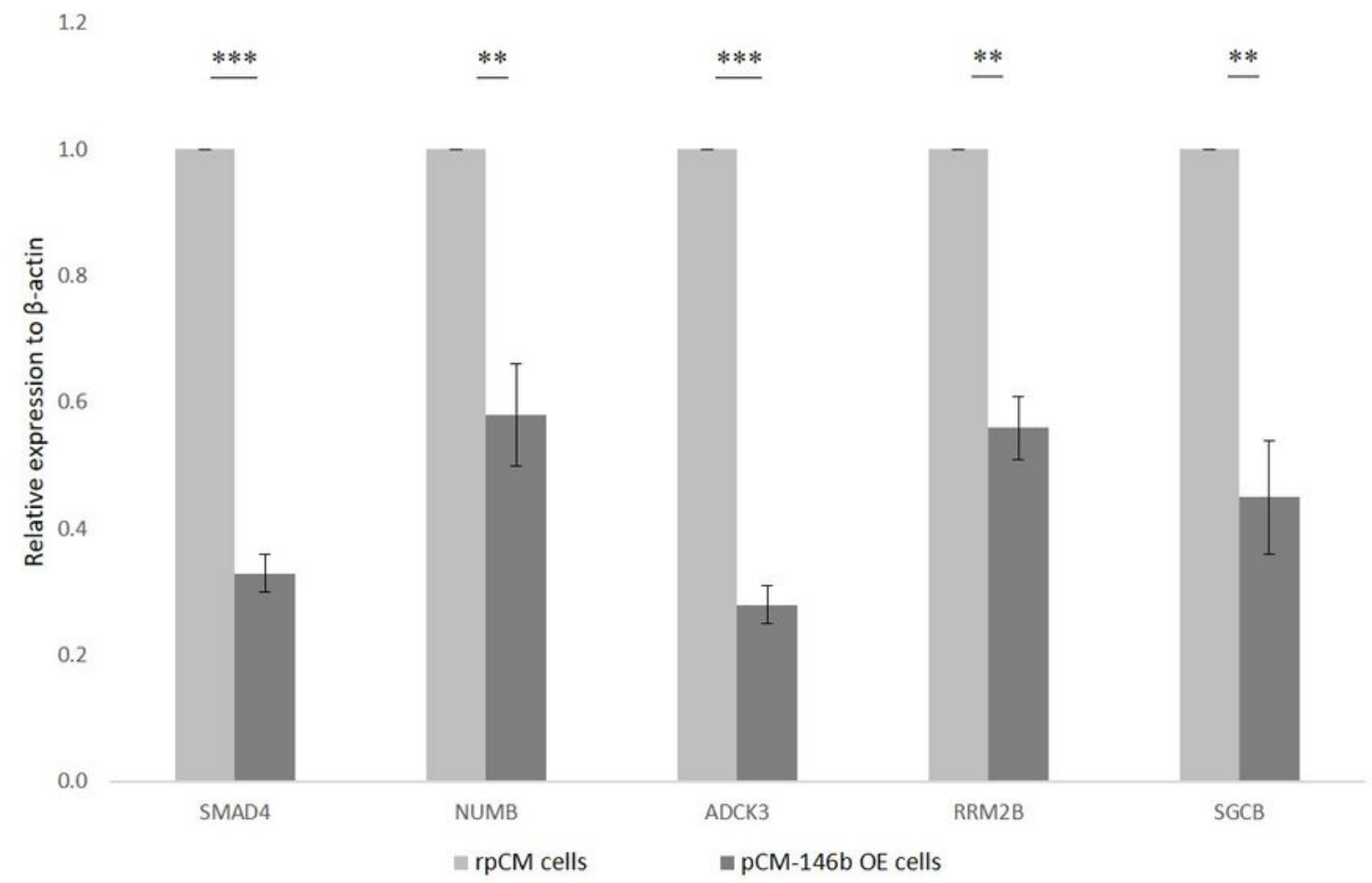

(B)

(C)
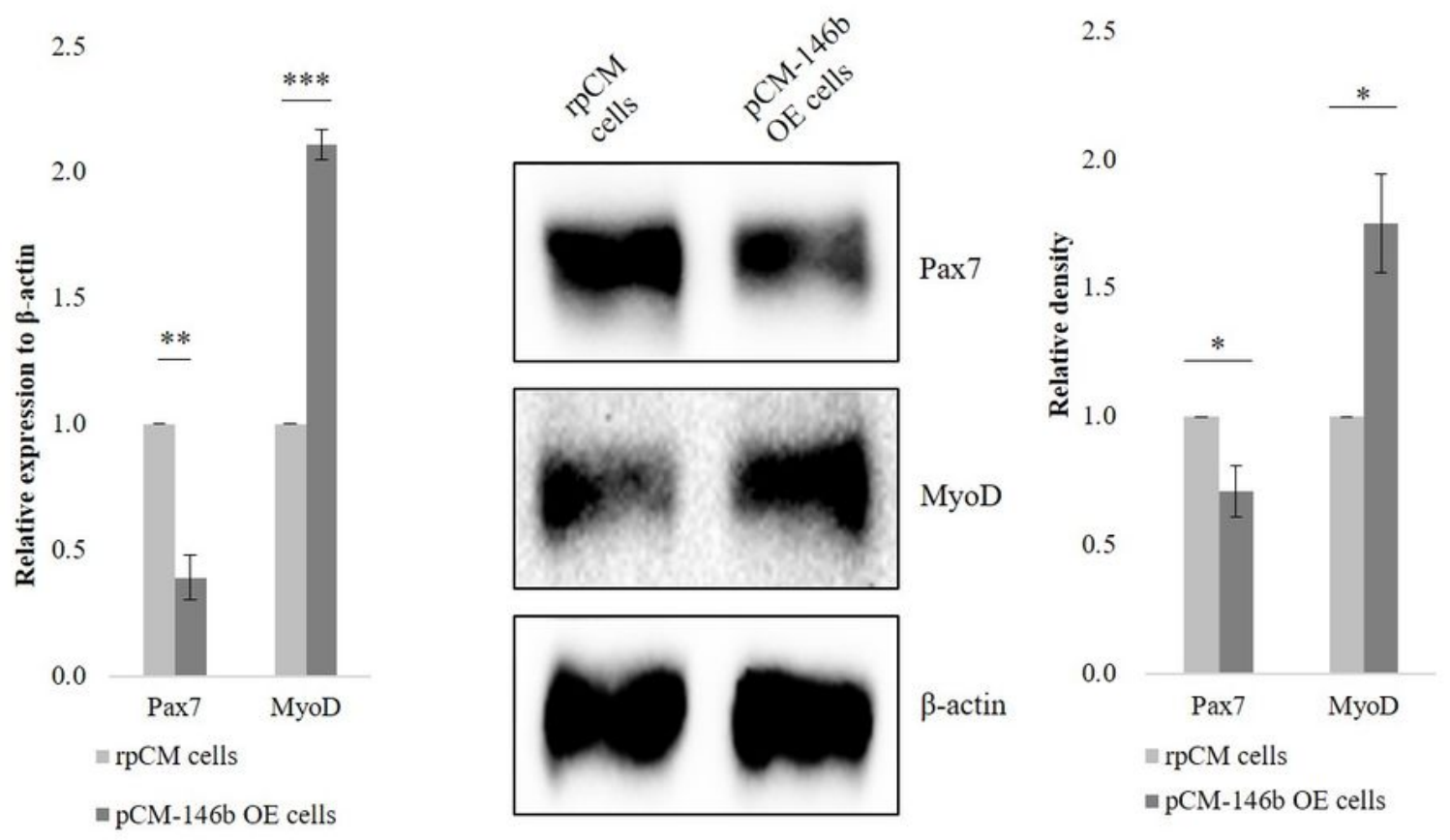

Figure 2

Gene expression analysis of undifferentiated chicken myoblast cells ( $r p C M$ vs. pCM-146b OE cells) by quantitative RT-PCR (qRT-PCR) and Western blotting. (A) mRNA expression profiles of target transcripts of miR-146b (SMAD4, NUMB, ADCK3, RRM2B and SGCB) were compared between regular pCM and pCM- 
146b OE cells by qRT-PCR (**p< 0.01, $\left.{ }^{\star \star \star} p<0.001\right)$. (B) mRNA expression profiles of Pax7, MyoD were compared between regular pCM and pCM-146b OE cells by qRT-PCR $\left(* \star p<0.01\right.$, $\left.{ }^{\star \star \star} p<0.001\right)$. (C) Protein expression profiles of Pax7 and MyoD were analyzed and compared between undifferentiated regular pCM and pCM-146b OE cells. The graph was presented by density comparison from each protein expression profile of Western blotting ( $\left.{ }^{*} p<0.05\right)$.

(A)

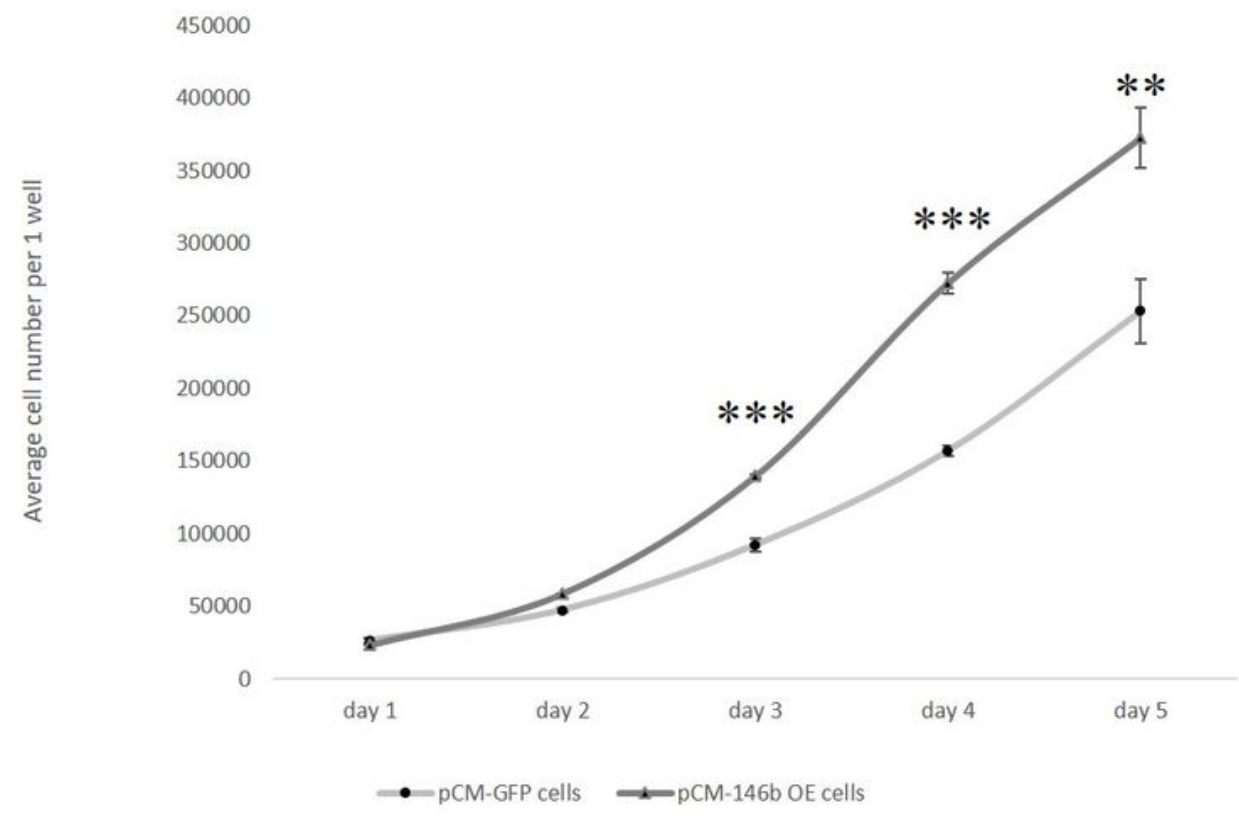

(B)

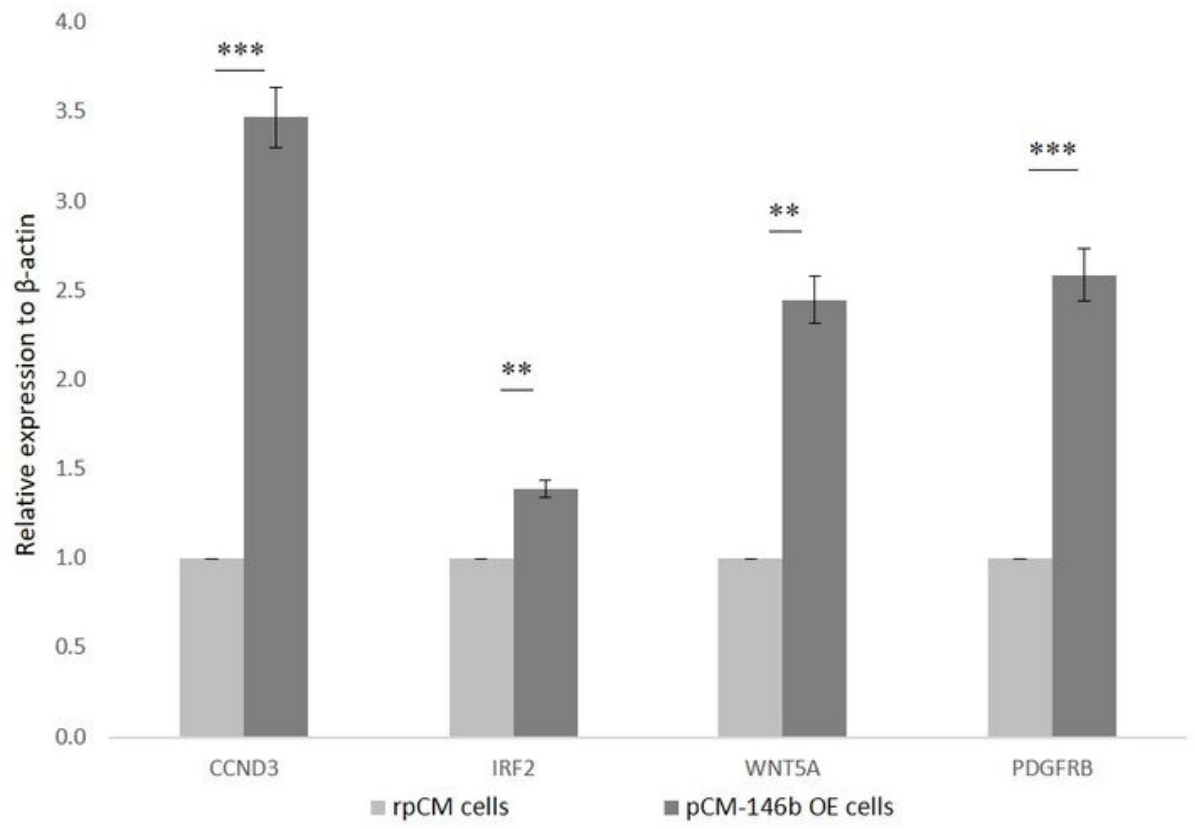

Figure 3 
Proliferation rate and gene expression analysis during chicken myoblast cells growth. (A) The cell proliferation rates were analyzed and compared between GFP-expressing pCM (pCM-GFP cells) and pCM146b OE cells during 5 days ( $* \star p<0.01$, $* \star \star p<0.001)$. (B) mRNA expression profiles of CCND3, IRF2, WNT5A, and PDGFRB were compared between regular pCM and pCM-146b OE cells by qRT-PCR $\left({ }^{* \star} \mathrm{p}<\right.$ $0.01, * * * p<0.001)$.

(A)

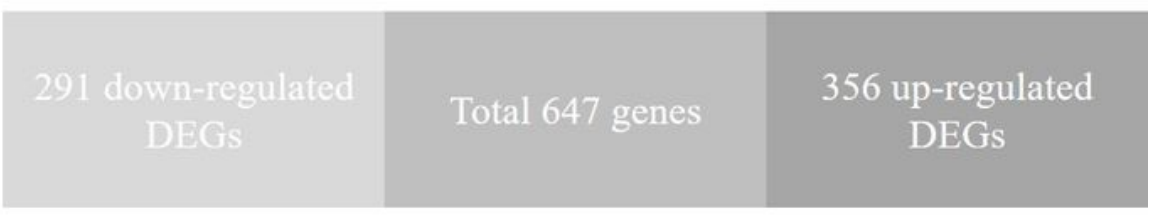

(B)

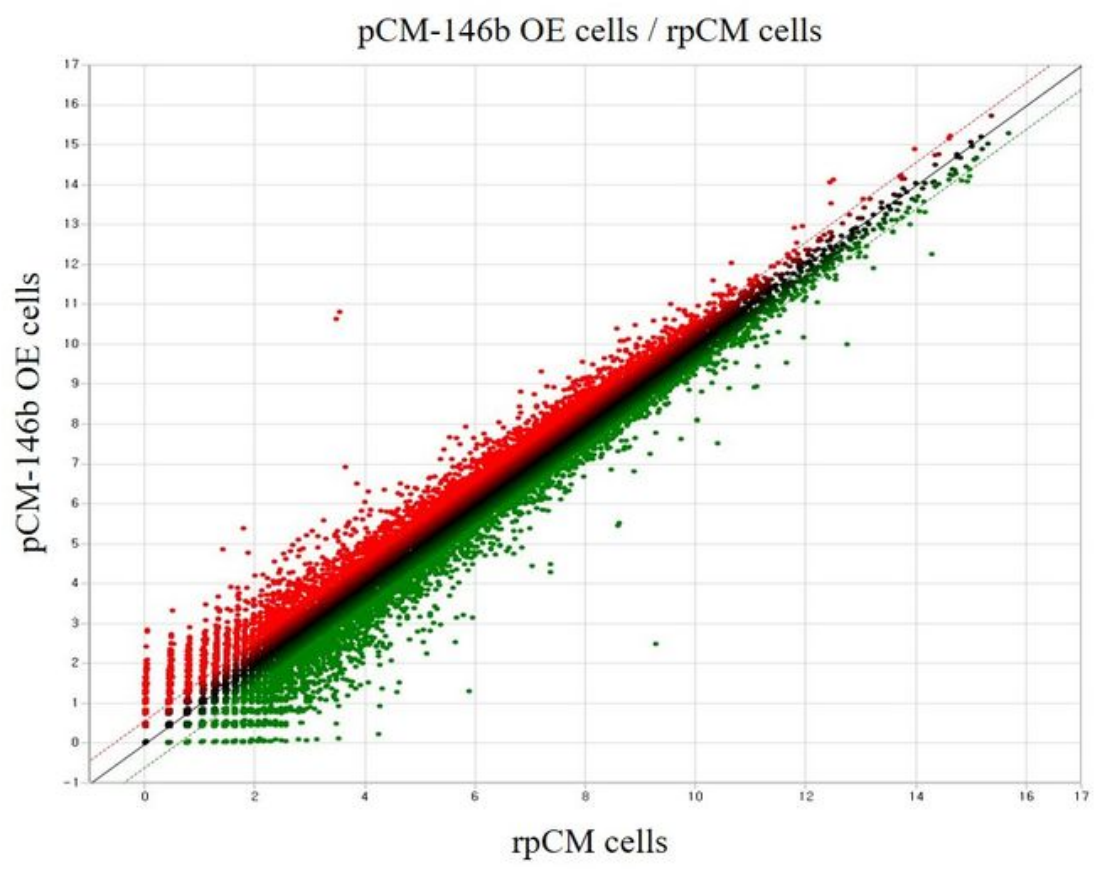

(C)

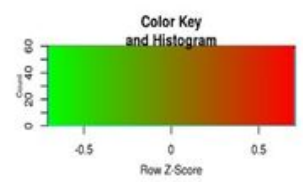

rPCM DEGs

pCM-146b OE DEGs

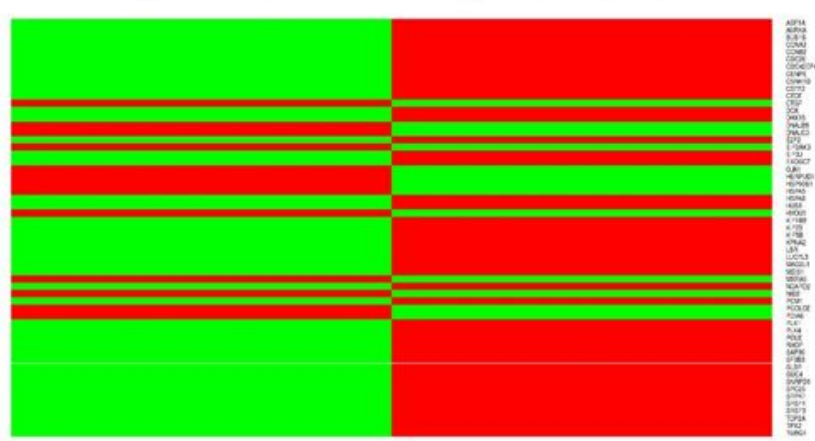

Figure 4 
mRNA sequencing analysis between the regular pCM cells and $\mathrm{pCM}-146 \mathrm{~b}$ OE cells. (A) Differentially expressed genes (DEGs) between the regular pCM cells and pCM-146b OE cells were identified with a $p$ value cut off at 0.001 and a fold change cut off at 1.5. (B) Scatter plot analysis of DEGs. The red and green dots indicate the expression patterns of the up-regulated and down-regulated genes in the $\mathrm{pCM}$ 146b OE cells, respectively. (C) Heat map analysis of DEGs. The red and greed heat maps demonstrate the expression of the up-regulated and down-regulated genes between regular pCM and pCM-146b OE cells.

(A)

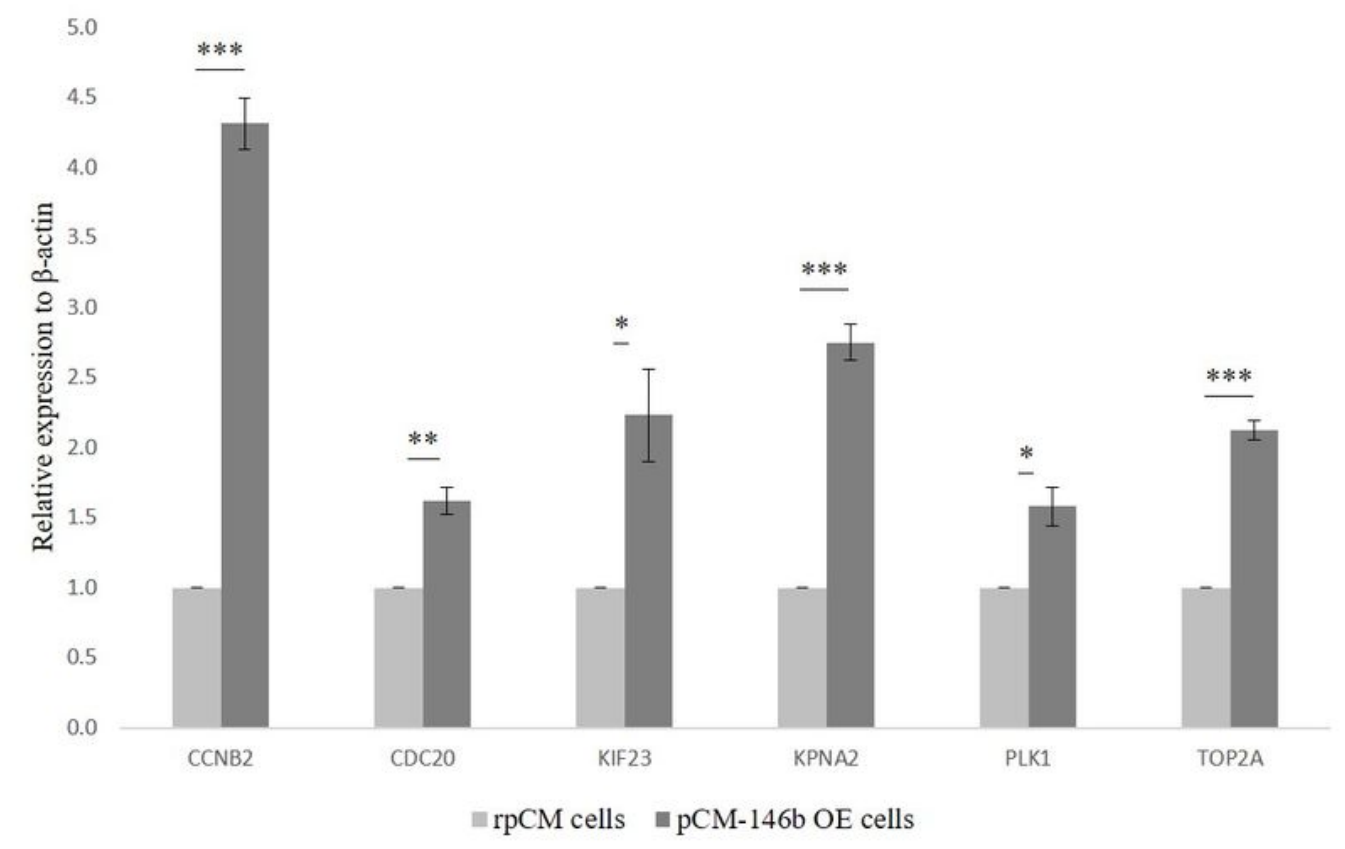

(B)

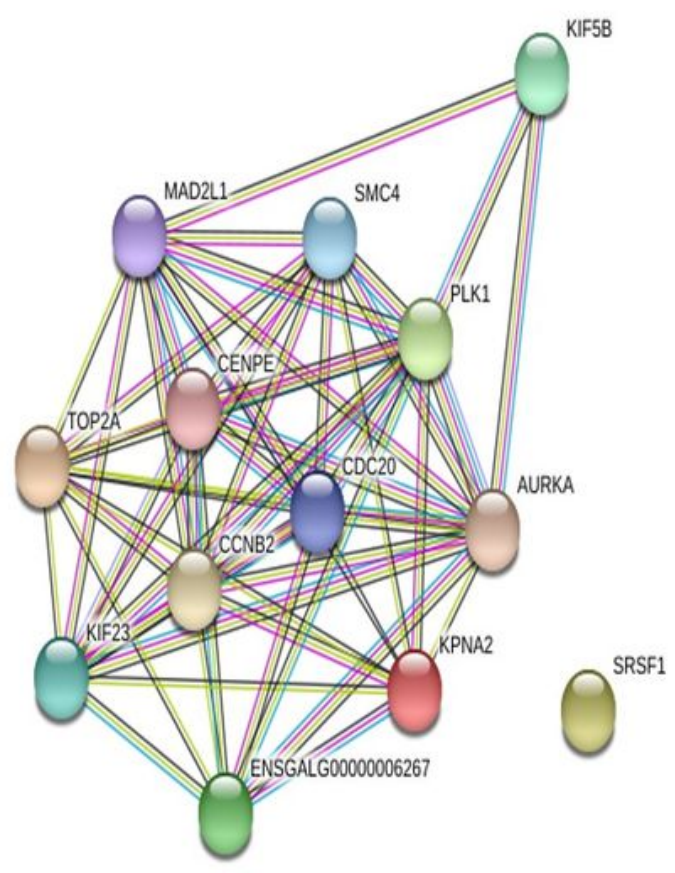




\section{Figure 5}

Validation of mRNA sequencing data and string analysis. (A) The expression profiles for the up-regulated genes (CCNB2, CDC20, KIF23, KPNA2, PLK1 and TOP2A) in the pCM-146b OE cells by qRT-PCR (** $\mathrm{p}<$ 0.001). (B) String analysis of the up-regulated gene sets in the pCM-146b OE cells.

(A)

rpCM cells

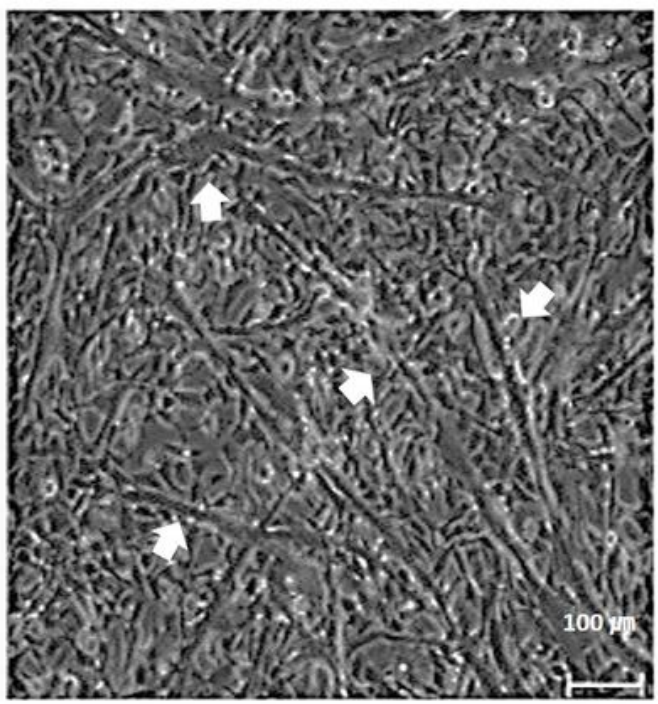

pCM-146b OE cells

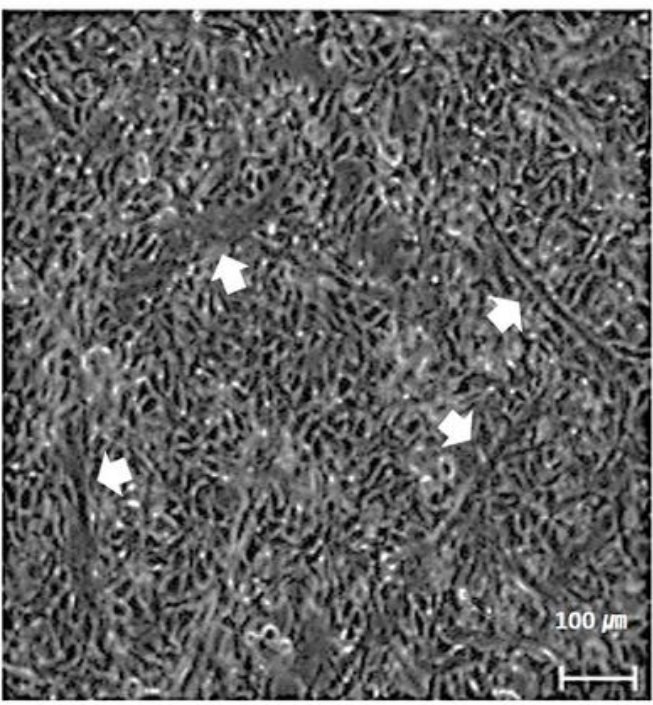

(B)

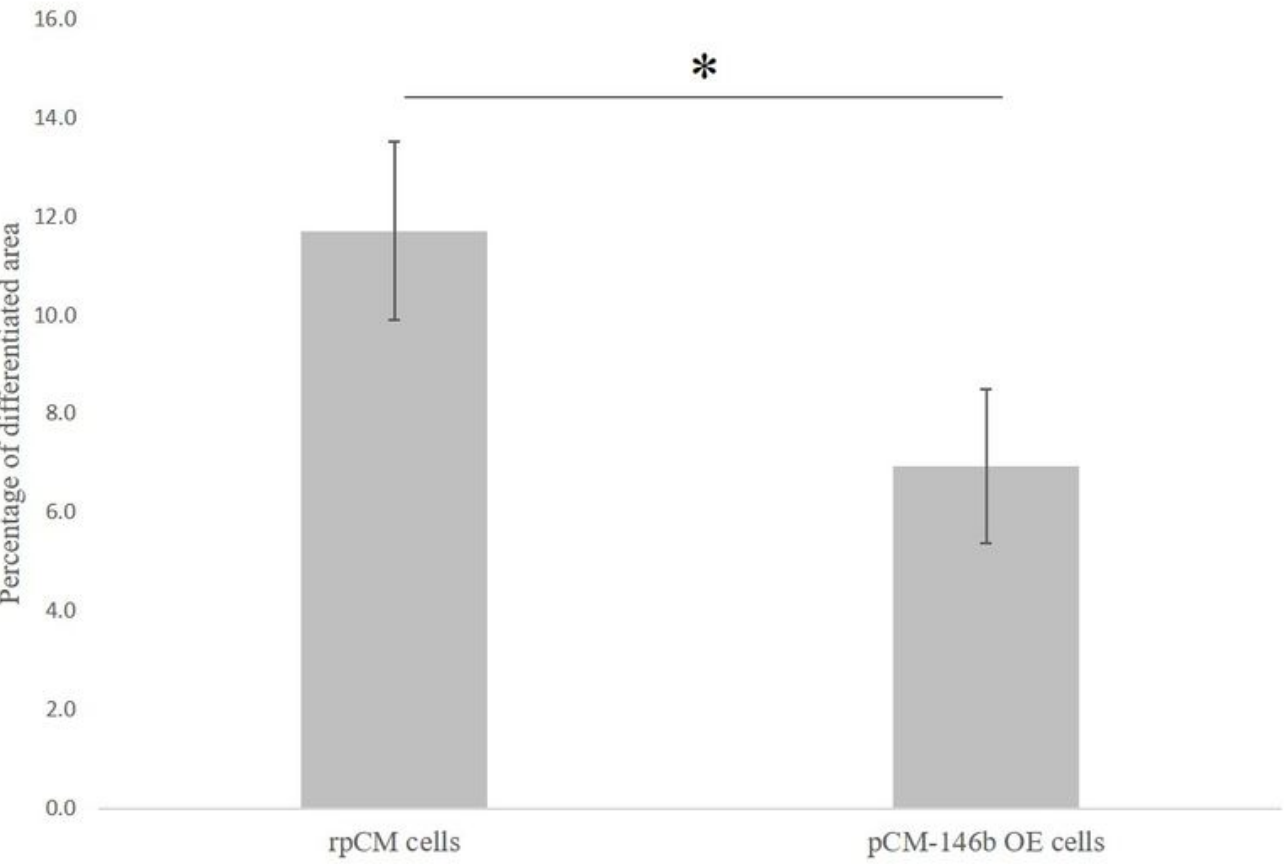

Figure 6 
Morphological analysis of differentiated pCM-146b OE cells. (A) Morphological comparison of the differentiated myotubes of regular $\mathrm{pCM}$ and $\mathrm{pCM}-146 \mathrm{~b}$ OE cells after 4 days under the differentiation condition. White arrows show the differentiated area (scale bar $=100 \rrbracket)$. (B) Comparison of the percentage of the differentiated area in the regular pCM and pCM-146b OE cells $\left({ }^{*} p<0.05\right)$.

(A)
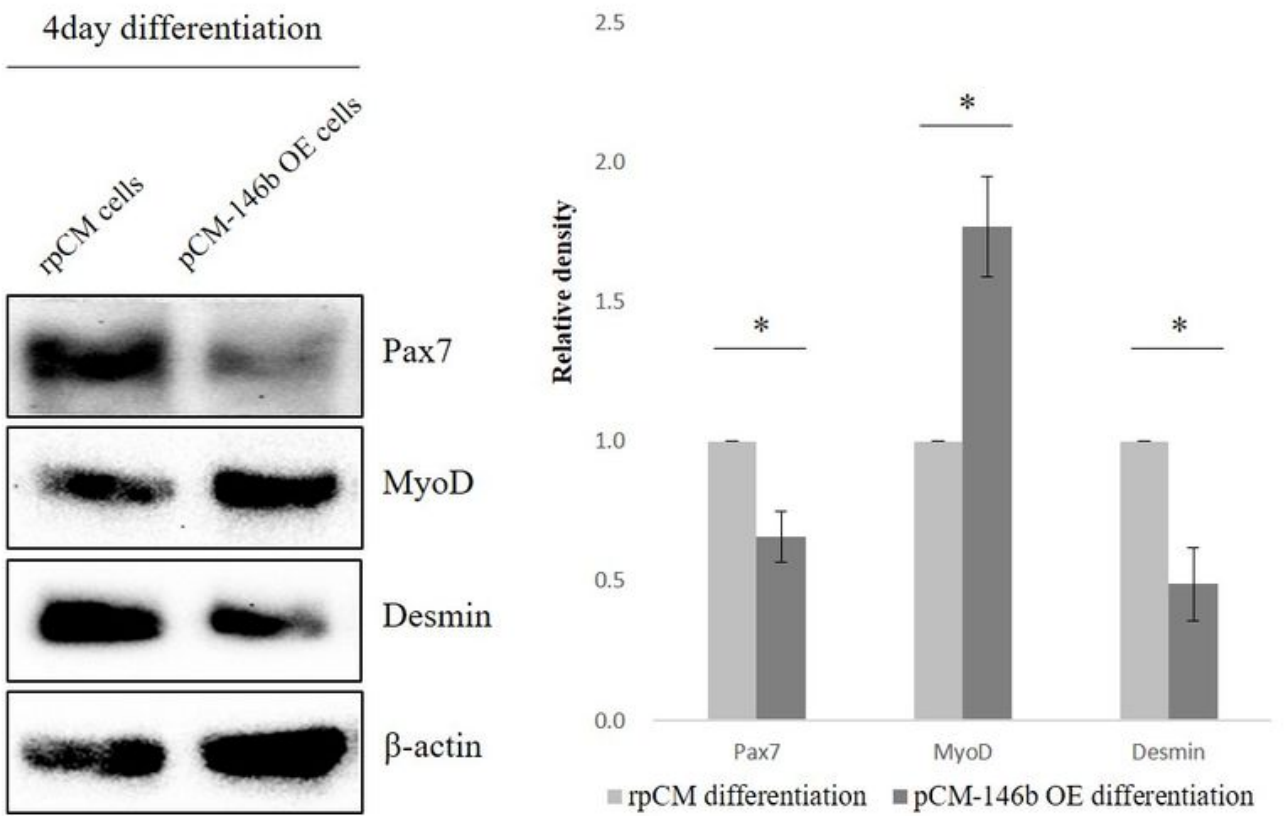

(B)

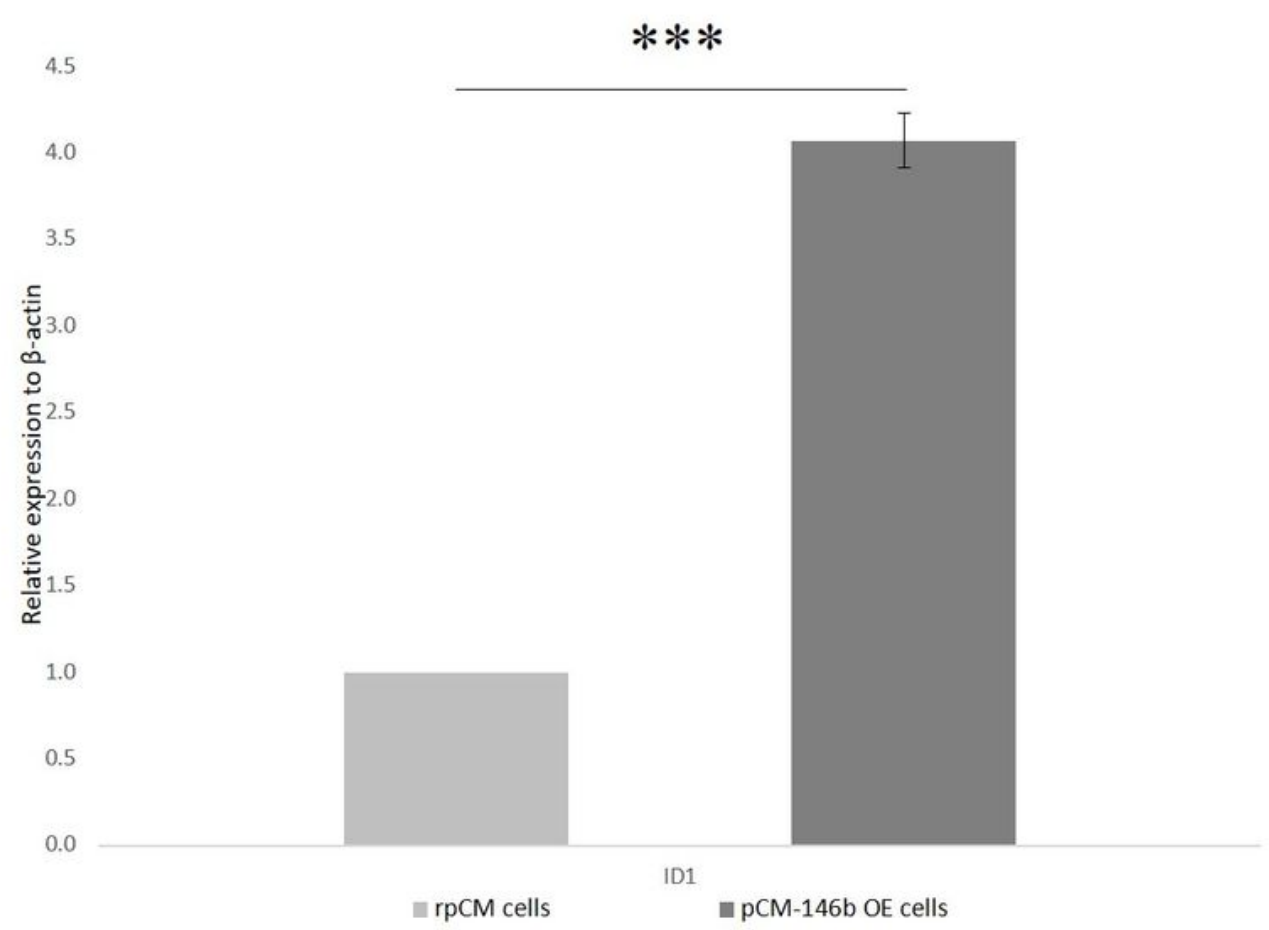

Figure 7 
Protein expression analysis during differentiation and ID1 expression analysis (A) Protein expression profiles of Pax7, MyoD and Desmin were analyzed and compared between regular pCM and pCM-146b $\mathrm{OE}$ cells after 4 days of myotube differentiation. The graph was presented by density comparison from each protein expression profile of Western blotting $\left({ }^{\star} p<0.05\right)$. (B) Expression profiles of ID1 gene was compared between the regular pCM cells and pCM-146b OE cells $(\star \star \star p<0.001)$. 